\title{
Determination of Platelet Parameters with Impedance Automated Analyzers in Diabetic Patients with Coronary Artery Disease
}

\author{
MARIA-CRISTINA APAVALOAIE (VLADEANU) ${ }^{1}$, IRIS BARARU BOJ AN ${ }^{1}$, OANA VIOLA BADULESCU ${ }^{1 *}$, CARMEN ELENA PLESOIANU ${ }^{2}$, \\ DANIELA J ITARU³, ANDREI BOJAN4*, DAN ILIESCU², PAUL-DAN SIRBU5*, MANUELA CIOCOIU¹, MAGDA BADESCU1, \\ CATALINA ARSENESCU GEORGESCU² \\ 'University of Medicine and Pharmacy Grigore T. Popa, Department of Morphofunctional Sciences, 16 Universitatii Str., 700115, \\ Iasi, Romania \\ ZUniversity of Medicine and Pharmacy Grigore T. Popa, Department of Medical Sciences, 16 Universitatii Str., 700115, Iasi, \\ Romania \\ ${ }^{3}$ University of Medicine and Pharmacy Grigore T. Popa, Department of Biochemistry, 16 Universitatii Str., 700115, Iasi, Romania. \\ ${ }^{4}$ University of Medicine and Pharmacy Grigore T. Popa, Department of Surgical Sciences, 16 Universitatii Str.,700115, Iasi, \\ Romania \\ EUniversity of Medicine and Pharmacy Grigore T. Popa, Department of Orthopedics and Traumatology, 16 Universitatii Str., \\ 700115, lasi, Romania
}

\begin{abstract}
Atherosclerosis and platelet activity are two important chain factors linked together in the onset and the severity of coronary artery disease. Our study included 60 diabetic patients with ischemic heart disease, all having underwent coronary angiography. In this substudy from a larger epigenetical and genetical study, we phocused on the interrelationship between vessel disease and primary hemostasis. The haematological parameters included were platelet count (PLT), the platelet distribution width (PDW), the mean platelet volume (MPV) and the platelet larger cell ratio $(P-L C R)$. ). The severity of the coronary disease was defined by the number of stenotic/occluded coronaryarteries. We demonstrated a positive corelation with the duration of diabetes ( $p=0.032)$, as $34 \%$ of the patients with a long duration of the diabetes had a higher number of platelets. The mean platelet volume was slightly elevated in diabetic females over 65 years old, compared to younger diabetic men, though not statistically significant $(p=0.101)$. Although the investigated parameters were mostly in the normal range, the fact that for some cathegories of patients they were orientated towards the upper limit, raises some questions for the next studies. Future adjustments of lot number and selection criteria for the following studies are needed. Using the MPV as a prediction test for cardiovascular complications is still a controversial subject, since the scientifical background contains both positive and negative studies on this matter.
\end{abstract}

Key words: platelets, primary hemostasis, coronary artery disease

Cardiovascular disease, mainly coronary artery disease, is the leading cause of death both in economically developed countries and in low-income regions of the globe [1]. Atherosclerosis can be hold accountable for most situations of coronary artery obstructions. The main contributing factors in the formation of atheroslerosis are high LDL-Cholesterol, a well known risk factor for cardiovascular disease [2], and dype 2 diabetes mellitus (T2DM) [3]. Coronary thrombosis, the main cause of coronary artery occlusion, is the result of disruption or fissuring of an atherosclerotic plaque, allowing thrombogenic material to be exposed to the blood flow. As a consequence, the coagulation cascade is activated and the blood clot is formed [4]. In addition, thrombi release vasoconstrictive substances such as thromboxane A2 [5], serotonin [6] and thrombin [7], which may explain persistent or recurrent occlusion, despite the possible mechanism of recanalization [8]. So, it seems possible that persistent occlusion may result both from spasm causing a plaque to rupture, and from plaque fissure in an arterial segment hypersensitive to the constrictor stimuli released by the developing thrombus [9]. Therefore we may draw the conclusion that platelets, representing primary hemostasis, are very important for the initiation and extension of coronary artery disease.

\section{Experimental part \\ Material and method}

This study was performed on a subgroup of 60 diabetic patients, included in a larger group of 154 patients with acute coronary disease, designed for investigating the role of the classic cardiovascular risk factors and the genetic polymorphisms of apoprotein B100 gene and the angiotensin converting enzyme gene. All patients gave their informed consent according to the Declaration of Helsinki II. For the present study phocusing on platelet parameters and the severity of coronary artery disease, we chose 60 diabetic patients with unstable angina or myocardial infarction, who performed coronary angiography at the Institute for Cardiovascular Disease George I.M. Georgescu, Iasi,Romania.

We evaluated clinical features such as: gender (men or women), age, duration of diabetes, height ( $\mathrm{cm}$, measured with a stadiometer), weight $(\mathrm{kg})$. The BMI $\left(\mathrm{kg} / \mathrm{m}^{2}\right)$ was calculated and included in a classification of the degree of obesity. Obese patients were defined as having BMI index superior to 30 and were divided in three grades: class I: BMI 30-34.9, class II: BMI 35-39.9, class III: BMI>40.

We collected blood samples from each patient, on EDTA, to prevent coagulation. The hematological tests were performed with impedance automated analyzer Ac.T 5 diff. (Beckman Coulter). In order to investigate the primary

*email: violabadulescu@yahoo.com; andreibojan@yahoo.com, pdsirbu@yahoo.com 
hemostasis we phocused on the platelet count (PLT), the platelet distribution width (PDW), the mean platelet volume (MPV) and the platelet larger cell ratio (P-LCR).

The severity of the coronary artery disease was evaluated by the number of diseased vessels, as revealed by the coronary angiography.

We used SPSS version 18 to perform the statistical analysis. ANOVA test was done in order to analyze the dispersion of the dependent variable: intra and intergroup. When assessing the significant difference between two or more groups, we used for the quantitative variables: the tstudent test and the $F$ test (ANOVA). To compare clinical and laboratory biochemical and physiological parameters in relation to the studied SNPs and nutritional status, the Kruskal-Wallis and Pearson correlation coefficient were done. Statistical significance was considered to be $p=0.05$.

\section{Results and discussions}

The number of platelets ranged between 186.000 and $310.000 / \mathrm{mm} 3$, with no significant differences between age, gender, body mass index and positive history of ischemic heart disease ( $p>0.05)$ (fig.1). However, the statistical analysis demonstrated a positive corelation with the duration of diabetes $(p=0.032)$. We observed that $34 \%$ of the patients with a long duration of the diabetes had a higher number of platelts.

The platelet distribution width (PDW) ranged between 10.90 to $16.40 \mathrm{fL}$. The analysis of the mean PDW revealed no statistical difference between genders ( 12.6 versus $12.98 \mathrm{Fl} ; p=0.432$ ), BMI ( 13.10 versus $12.79 \mathrm{fL} ; p=0.668$ ) and history of ischemic heart disease (12.71 versus 13.06 $\mathrm{fL} ; \mathrm{p}=0.471)$. The mean values of PDW were significantly lower for the patients under 65 years old ( 12.46 versus $13.36 \mathrm{fL} ; p=0.039$ ). We found a direct corelation with the long history of diabetes $(r=-0.296 ; R 2=0.0874 ; p=0.064)$, but our results cannot be extrapolated to the general population.

The MPV ranged between 8.10 and $12.30 \mathrm{fL}$ (fig.2). We obtained significantly higher values in women (10.27 versus $9.52 \mathrm{fL} ; p=0.05$ ) and higher values, but not statistically significant, in elder patients over 65 (10.31 versus $9.65 \mathrm{fL} ; p=0.101$ ). As for the $B M I$ variations and hystory of ischemic heart disease, we recorded small, nonsignificant differencies: 9.65 versus $9.94 \mathrm{fL} ; p=0.661$ and 9.97 versus $9.78 \mathrm{fL} ; p=0.652$. We also found an indirect corelation between MPV variations and the duration of diabetes, but not enough to be extrapolated to the general population $(r=-0.203, p=0.208)$.

The P-LCR ranged between $25.30 \%$ and $38.90 \%$. The mean P-LCR value was slightly increased in women ( 30.02 versus 29.29\%; $p=0.540$ ), patients over 65 years old ( 31.55 versus $28.43 \% ; p=0.007$ ) and overweight patients (31 versus 29.53\%; $p=0.460$ ). As for the duration of diabetes, $42 \%$ of our patients, with a long history of diabetes, had significantlylower P-LCR $(p=0.002)$.

All patients had a normal plachetocrit. There were no significant differences between genders $(0.272$ vs $0.280 \%$; $p=0.153)$, age cathegories ( 0.273 vs $0.280 \% ; p=0.270)$, BMI ( 0.283 vs $0.275 \% ; p=0.466)$ and ichemic heart disease history ( 0.274 versus $0.280 \% ; p=0.378$ ). There was a small indirect corelation between plachetocrit and diabetes duration, but not enough for statistical significance ( $r=-$ $0.232 ; p=0.149$ ).

As for the severity of the coronary disease, our patients were both multivessel diseased and no vessel diseased
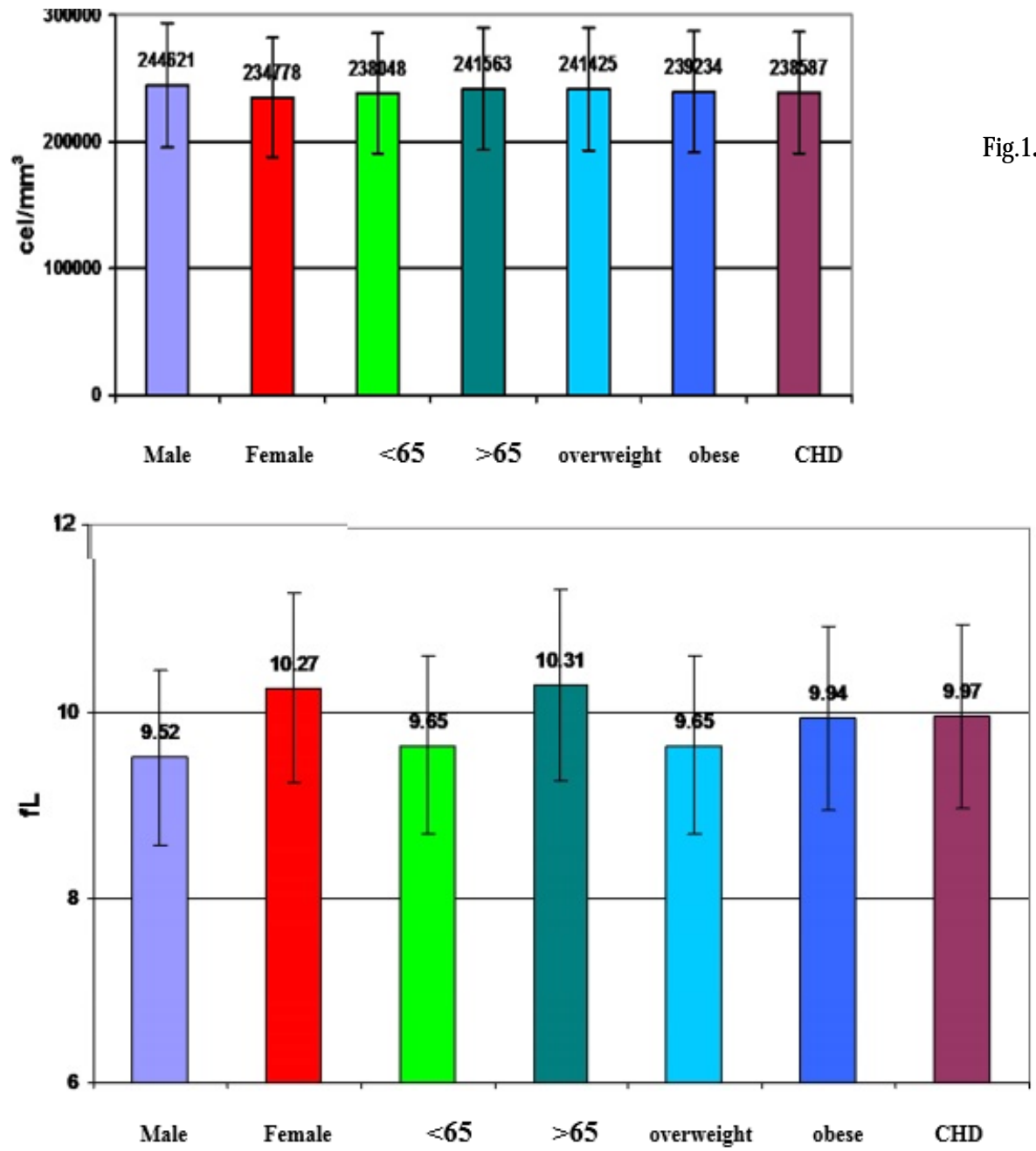

Fig.1. Mean platelet values according to the epidemiological characteristics

Fig.2. Mean MPV values according to the epidemiological characteristics 
(patients with artery stenosis $<60-70 \%$ ). Out of the 60 patients included, 3 were no-vessel diseased, 25 had onevessel disease, 19 were two-vessel diseased and 13 had three-vessel disease. The higher values for MPV were found in the patients with more severe coronary lesions, butthere was no statistical significance $(p=0.062)$.

Our results proved that patients with a long history of diabetes have a higher number of platelets, with a higher MPV for diabetic patients over 65 years old. Several previous studies have analised the relationship between MPV, platelet count and atherosclerosis. Uysal H.B. etal., claimed that a possible explanation for this relationship might be the increase in the metabolic and enzymatic activation of platelets and the increased secretion of mediators from the hemostatically active and larger platelets [10] . Female diabetic patients with a long duration of the disease are even more predisposed to a higher number of platelets with larger platelet volume. Although our analysis was not statisticaly significant, and therefore not extrapolable, our results were concordant with those from other studies. Sterner et al., observed a connection between raised platelet number and diabetic female gender. He also noted that diabetic nephropathy is related to platelet count and function, so platelet count might be a future prognostic indicator for diabetic complications, opening new study directions [11]. The indirect corelation between mean platelet volume and diabetes duration was not what we expected, since larger platelets are thought to be more active and thrombogenic than normal or smaller ones. However, Demirtunc etal. raised the the hypothesis of rapid consumption of activated platelets in diabetes with complications, leading to a not significantly different MPV [12].

There have been several discussions over the time both about the basic technique (impedance versus optical method) and the anticoagulant in the collection tube (EDTA versus MgSO4). Also, the time between blood collection and analysis seems to make a considerable difference. If determinations are not performed in maximum one hour, errors are most likely to appear. Some scientists outlined that platelets swell in the EDTA, which leads to a false increase in the MPV [13]. Others incriminated the optical light scatter system for errors in the determination of MPV, as the dilution of cytoplasmic contents,leading to a decrease in light scatter, result in measuring smaller MPVs [14]. Segal et al. noted that impedance platelet counting methods on different analysers may give different results of the same sample, due to the differences in method, linearity over the entire range and the number of cells counted [15]. It seems that the best technique is immunofluorescence count, but most haematology laboratories lack the time, skills and facilities for this [15]. Our tests were performed with impedance method, in the one hour interval and on EDTA.

\section{Conclusions}

Primary hemostasis parameters are an important piece in the puzzle of coronary artery disease. Literature data on this topic brings both positive and negative studies. Some of our results agreed with the findings in other studies, but since our evidence is not statistically strong enough, we take into consideration a new, larger study, with three vessel disease patients only, with more complications, other than the cardiovascular ones and the inclusion of more haematological parameters, like antithrombin III activity, thromboxan A2 level and plasminogen activity inhibator activity.

\section{References}

1.NABEL E.G, BRAUNWALD E. A tale of coronary artery disease and myocardial infarction. The New England J ournal of Medicine 2012; 366:54-63.

2. BADESCU C., REZUS E., BADESCU L., DIMA N., REZUS C. New Drugs for Lowering LDL Cholesterol. The Medical-Surgical J ournal 2016; 120(3): 485-490.

3.GILCA G.E., STEFANESCU G., 0. BADULESCU 0. et al. Diabetic cardiomyopathy: current approach and potential diagnostic and therapeutic target. J ournal of Diabetes Research. volume 2017, article ID 1310265, 7 pages.

4.KRISTENSEN S.D., LASSEN J.F., RAVN H.B. Pathophysiology of coronary thrombosis. Seminars in Interventional Cardiology 2000; 5(3): 109-115.

5.ELLIS E.F., OELZ O., ROBERTS I.J., et al. Coronary smooth muscle contraction by a substance released from platelets: evidence thst is Thromboxane A2. Science 1977; 193:1135.

6.BRAZENOR R.M., ANGUS J.A. Actions of serotonin antagonists on dog coronary artery. European J ournal of Pharmacology 1982; 81: 569. 7.HAVER V.M. NAMM D.H. Characterization of the thrombin induced contraction of vascular smooth muscle. Blood Vessels 1984; 21: 53. 8.MASERI A., L'ABBATE A., BAROLDI G., et al. Coronary vasospasm as a possible cause of myocardial infarction: a conclusion derived from the study of preinfarction angina. New England Journal of Medicine 1985; 299: 1271.

9.MASERI A., CHIERCHIA S., DAVIES G. Pathophysiology of coronary occlusion in acute infarction. Circulation 1986; 73(2): 233-239.

10.UYSAL H.B., DAGLI B., AKGULLU C. et al. Blood count parameters can predict the severity of coronary artery disease. Korean Journal of Internal Medicine 2016; 31: 1093-1100.

11.STERNER G., CARLSON J., EKBERG G. Raised platelet levels in diabetes mellitus complicated with nephropathy. Journal of Internal Medicine 1998; 244: 437-441.

12.DEMIRTUNC R., DUMAN D., BASAR M., BILGI M.,TEOMETE M., GARIP T. The relationship between glycemic control and platelet activity in type 2 diabetes mellitus. Journal of diabetes complications2009; 23(2): 89-94.

13.BOWLES K.M., COOKE L.)., RICHARDS E.M., BAGLIN T. Platelet size has diagnostic predictive value in patients with thrombocytopenia. Clinical Laboratory of Haematology 2005; 27: 370-373.

14.PATTERSON K. Platelet parameters generated by automated blood counters. CME Bulletin Haematology 1997; 1: 13-16.

15.SEGAL H., BRIGGS C., KUNKA SET al. Accuracy of platelet counting haematology analysers in severe thrombocytopenia and potential impact on platelet transfusion. British J ournal of Haematology 2005; 128: 520-525.

16.BRIGGS C.J., MACHIN S.J. Discrepancy between impedance and immunofluorescence platelet counting has implications for clinical decision making in patients with idiopathic thrombocytopenia purpura. British J ournal of Haematology 2006; 135(3): 416-417.

$\overline{\text { Manuscript received.14.11.2018 }}$ 